\title{
Run Marco e o Pensamento Computacional: possibilidades para a Educação Infantil
}

\author{
Hanna Almeida Sousa ${ }^{1}$, Maria Auricélia da Silva ${ }^{2}$ \\ ${ }^{1}$ Geografia - Universidade Federal do Ceará (UFC) - Campus do Pici - Bloco 911- \\ Fortaleza-CE - Brasil \\ ${ }^{2}$ Unidade Universitária de Educação Infantil Núcleo de Desenvolvimento da Criança - \\ Universidade Federal do Ceará (UFC) - Campus do Pici - Bloco 859 - Fortaleza-CE - \\ Brasil \\ hannaalso04@gmail.com, silvauricelia@gmail.com
}

\begin{abstract}
This work presents the use of a game by children of 4 and 5 years old in a public institution of Early Childhood Education, in order to work on problem solving from the perspective of Computational Thinking. General objective: to analyze the use of the Run Marco Game, from the perspective of Computational Thinking, with children from early childhood education. Specific objectives: to understand the degree of interest of children in a game that proposes challenges and logical reasoning; check the problem solving strategies used by children. We used qualitative research of an interpretative character in the analysis of the results, which showed the interest of the children in the proposed game and the strategies used to solve problems.
\end{abstract}

Resumo. Este trabalho apresenta o uso de um jogo por crianças de 4 e 5 anos de idade em uma instituição pública de Educação Infantil, a fim de trabalhar a resolução de problemas na perspectiva do Pensamento Computacional. Objetivo geral: analisar o uso do Jogo Run Marco, na perspectiva do Pensamento Computacional, com crianças da Educação Infantil. Objetivos específicos: perceber o grau de interesse das crianças por um jogo que propõe desafios e raciocínio lógico; verificar as estratégias de resolução de problemas utilizadas pelas crianças. Utilizamos a pesquisa qualitativa de caráter interpretativo na análise dos resultados, os quais demonstraram o interesse das crianças pelo jogo e as estratégias usadas para a resolução de problemas.

\section{Introdução}

A utilização de jogos digitais como ferramentas pedagógicas pode auxiliar no desenvolvimento e na aprendizagem das crianças, devido ao fato de estas já estarem inseridas em uma sociedade tecnológica, não sendo mais possível o distanciamento das Tecnologias Digitais de Informação e Comunicação (TDIC) do processo formativo do indivíduo.

As Diretrizes Curriculares Nacionais para a Educação Infantil - DCNEI [Brasil 2010] apontam para a necessidade do uso de tecnologias digitais como ferramentas que possibilitam a aprendizagem. Uma das competências presentes na Base Nacional Comum Curricular - BNCC [Brasil 2018] diz respeito à utilização das TDIC de forma crítica, significativa, reflexiva e ética nas diversas práticas sociais. 
Diante dessas recomendações, é importante ressaltar que as tecnologias não podem ser usadas como um fim no processo educacional, mas como um suporte que possibilita diversas experiências de aprendizagem. Papert (1985) pensava o computador como uma ferramenta que carrega germes ou sementes culturais que, quando colocados no terreno fértil do intelecto, irão se desenvolver. A partir disso, é necessária uma abordagem pedagógica por trás da utilização das ferramentas digitais, para que se possa verificar o benefício de seus usos.

O Pensamento Computacional (PC), ou Computational Thinking, conceito criado por Wing (2006) foi utilizado como base para a pesquisa e interpretação de dados obtidos a partir das observações feitas no desenvolvimento deste trabalho, porque possibilita o pensamento crítico e a resolução de problemas, habilidades importantes de serem trabalhadas desde a Educação Infantil. Wing (2008) reforça que as abordagens do PC não necessariamente requerem a utilização de máquinas e favorecem o desenvolvimento da aprendizagem em várias áreas científicas, pois constituem uma estratégia para a resolução de problemas.

Algumas atividades cotidianas realizadas pelas crianças podem ser vistas sob a perspectiva do PC. Como exemplo, podemos pensar que a organização dos brinquedos, após uma brincadeira, torna-se um desafio que necessita de resolução, pois algumas questões surgem: "qual a melhor maneira de organizá-los? Tenho que dividir e/ou agrupar os brinquedos? Quais as etapas da organização?”. Assim, as características necessárias durante esse processo são: decomposição, para separar os brinquedos de modo a facilitar a organização; abstração, para escolher o que deve ser guardado em caixas separadas e ignorar o que não necessita ser compartimentado; reconhecimento de padrões; e algoritmo, quando se trata de uma sequência de etapas que a criança estabelece para organizar os brinquedos.

Nesse sentido, a utilização de jogos digitais como ferramentas de desenvolvimento da lógica possibilita a diversificação de experiências de aprendizagem no ambiente escolar, fazendo com que este seja, cada vez mais, motivador e desafiador para as crianças.

A partir dessas ideias iniciais, surgiu o problema desta pesquisa, que consistiu em indagar se crianças da Educação Infantil, de quatro (4) e cinco (5) anos, apresentariam interesse e engajamento por um jogo que propõe desafios e aborda as habilidades do PC. Assim, foi definido o objetivo geral deste trabalho, qual seja: analisar o uso do Jogo Run Marco, na perspectiva do Pensamento Computacional, com crianças da Educação Infantil. Os objetivos específicos foram: perceber o grau de interesse das crianças por um jogo que propõe desafios e raciocínio lógico; verificar as estratégias de resolução de problemas utilizadas pelas crianças.

O locus desta pesquisa foi a Unidade Universitária de Educação Infantil Núcleo de Desenvolvimento da Criança, da Universidade Federal do Ceará. A abordagem qualitativa de caráter interpretativo apoiou a análise dos dados coletados por meio da observação participante.

Este trabalho está assim estruturado: a introdução apresenta uma ideia geral sobre o problema da pesquisa, os objetivos do estudo, o locus e a metodologia; o quadro teórico traz uma discussão sobre o uso de recursos digitais na Educação Infantil, os fundamentos do Pensamento Computacional e a discussão de alguns trabalhos que abordam essa temática. Na sequência, são apresentados a metodologia, os resultados obtidos, as 
questões relevantes e a conclusão deste estudo.

A seguir, será apresentada a fundamentação teórica que ofereceu suporte à realização deste trabalho.

\section{Quadro Teórico}

As Diretrizes Curriculares Nacionais para a Educação Infantil [Brasil 2010] propõem a necessidade de as instituições de Educação Infantil garantirem experiências que "possibilitem a utilização de gravadores, projetores, computadores, máquinas fotográficas e outros recursos tecnológicos e midiáticos", reconhecendo a importância da utilização de diversas linguagens no âmbito escolar.

Uma das competências apontadas na Base Nacional Comum Curricular [Brasil 2018] traz a importância de "formular e resolver problemas e criar soluções (inclusive tecnológicas) com base nos conhecimentos das diferentes áreas". Nesse contexto, encontramos autores alinhados com essa perspectiva delineada nesses documentos oficiais que regulamentam as práticas na educação.

Ao perceber o avanço das tecnologias nos vários âmbitos sociais, Kenski (2007, p. 21) defende que "o homem transita culturalmente mediado pelas tecnologias que lhe são contemporâneas. Elas transformam sua maneira de pensar, sentir e agir”. Sobre isso, Ramos e Espadeiro (2014) também pensam que "as tecnologias têm, neste tipo de sociedade, um papel de grande relevo, até porque os estudantes e os professores são utilizadores de tecnologias em diferentes contextos e para diferentes finalidades".

Como as máquinas estão presentes de forma intensa no cotidiano, seu uso pode contribuir para desafiar a capacidade de pensar e resolver os problemas apresentados em uma atividade diária. Contudo, entender e interpretar a tecnologia e os dados não deve ser tarefa restrita aos cientistas da computação. Para Wing (2006), o PC se fundamenta no processo de formulação e solução de problemas, recorre a várias ferramentas mentais, podendo tratar um desafio complexo em partes mais simples, sendo uma habilidade que todos podem utilizar, não somente profissionais que se utilizam do computador (máquina) para resolver situações desafiadoras.

Segundo as Diretrizes para ensino de Computação na Educação Básica [SBC 2018, p. 5], o PC "vem sendo considerado como um dos pilares fundamentais do intelecto humano, junto com a leitura, a escrita e a aritmética pois, como estas, serve para descrever, explicar e modelar o universo e seus processos complexos".

A necessidade de inclusão do uso das tecnologias visando ao desenvolvimento de habilidades do PC advém da importância de instigar as crianças a resolverem problemas reais a partir dessa abordagem. Sobre isso, Santana e Oliveira (2019, p. 159) esclarecem que "aplicar as técnicas de programação em contextos interdisciplinares como prática pedagógica na Educação Básica visa promover o desenvolvimento do Pensamento Computacional (PC) dos estudantes".

Sendo assim, do ponto de vista pedagógico, a utilização das tecnologias pensadas para o desenvolvimento da lógica "desencadeia a evolução das capacidades pessoais dos alunos, como a capacidade de concentração, percepção e criatividade" [Kotz e Kovatli 2019, p. 2]. 
Sobre as crianças em idade pré-escolar, Papert (2008, p. 24) afirma que o conhecimento pode ser "metabolizado, assimilado juntamente com todas as outras experiências diretas do mundo". Isso demonstra que as crianças, nas relações que estabelecem vivenciando os ambientes com os quais interagem, podem aprender com mais facilidade e de forma lúdica. Nesse sentido, o uso de jogos é proposto como uma forma de interação criança-máquina por meio da qual a criança tem liberdade para experimentar, acertar, errar, observar os resultados do seu erro e tentar novamente.

É importante observar que a utilização de jogos na educação não deve ser feita de forma desvinculada de uma proposta educacional que apresenta objetivos bem definidos. Meira e Blikstein (2020) defendem que educadores e desenvolvedores de jogos trabalhem de forma colaborativa na produção desses recursos, o que reforça a importância de que a educação e as tecnologias sejam pensadas de forma a possibilitar diversas experiências de aprendizagem.

Prensky (2001) considera o uso de jogos como a melhor forma de trabalhar com os Nativos Digitais (geração influenciada pelas tecnologias), devido à linguagem familiarizada com os games. Além disso, o autor reforça a importância de os educadores pensarem, cada vez mais, em metodologias de aprendizagem nas mais diversas áreas, sendo necessário que as pesquisas e os jogos já desenvolvidos sejam bastante divulgados.

Os jogos digitais oferecem características lúdicas atrativas, que podem favorecer a aprendizagem, por isso devem ser inseridos como metodologia que oportuniza uma diversidade de experiências educativas. Segundo Abbasi, Ting e Hlavacs (2017), aspectos como imersão, fluidez mental, prazer e diversão, entretenimento, presença e motivação são apenas algumas das dimensões típicas dos estados de engajamento dos indivíduos com videogames.

Silva e Guarda (2019) utilizaram o jogo digital Run Marco como base para a realização de atividade com Computação Desplugada (CD). Assim, o Projeto Logicamente, apresentado no artigo, buscava atender às necessidades do trabalho com a lógica de programação e o PC, objetivando o desenvolvimento da aprendizagem. O relato de experiência apresentado tinha como temática principal a Segurança da Informação por meio da criptografia, e o público-alvo eram alunos das séries finais do Ensino Fundamental (de $6^{\circ}$ a $8^{\circ}$ ano).

A experiência documentada por Gomes, Melo e Tedesco (2016) apresenta o ensino de programação utilizando jogos digitais em uma escola particular com vinte (20) crianças de faixa etária entre cinco e seis anos. A iniciativa surgiu com o interesse de introduzir conceitos de programação. Os jogos utilizados foram Ninja Shape, The Foos, Code Baymax, Lightbot, Code Monkey e atividade de laboratório (Code.Org). Os resultados obtidos apresentaram possibilidades do uso de jogos para trabalhar com a programação nas faixas etárias indicadas. No entanto, o estudo revelou alguns desafios relacionados à interface dos jogos, pois esta não era considerada adequada, por não se valer das especificidades de compreensão leitora textual e simbólica do público-alvo.

O relato de Carlos, Godinho e Gomide (2018) apresentou, com a Escola de Verão de Programação de Macaé-RJ, a experiência do ensino de programação nas férias escolares, baseando-se em métodos lúdicos com o uso de jogos. Participaram da experiência cinquenta e oito (58) crianças, com idades entre cinco (5) e doze (12) anos. Mais de $50 \%$ dos participantes eram da rede pública. Ao final do curso, $100 \%$ dos aprendizes classificaram sua experiência de forma positiva. As ferramentas utilizadas 


\section{foram: Code Studio, Scratch, Monster Coding, Pencil Code e Code Monkey.}

Tomando como base a revisão de literatura dos últimos quatro anos dos anais do Congresso sobre Tecnologias na Educação (CTRL+E), do Workshop de Informática na Escola (WIE) e da Revista Brasileira de Informática na Educação (RBIE), é possível verificar uma escassez de trabalhos que apresentem o uso de Jogos Digitais na Educação Infantil, sendo as experiências práticas, de modo geral, voltadas ao Ensino Fundamental e ao Ensino Médio. Isso também é válido para a busca utilizando o termo "pensamento computacional", pois, apesar de ser possível encontrar estudos sobre as experiências utilizando jogos digitais na perspectiva do $\mathrm{PC}$, ainda há uma lacuna em relação à Educação Infantil.

Dessa forma, é importante reforçar a necessidade de pensarmos, cada vez mais, sobre essas abordagens, a fim de explorar o uso de recursos educacionais digitais, na perspectiva do Pensamento Computacional, com crianças da Educação Infantil.

\section{Métodos}

O desenvolvimento desta pesquisa se deu por intermédio da abordagem qualitativa de caráter interpretativo, de modo a possibilitar a organização dos dados descritivos obtidos mediante a interação direta com os objetos de estudo.

Foi de fundamental importância a observação participante para compreender os comportamentos dos sujeitos presentes. A partir de registros em diário de bordo, fotografias, gravações e interações diretas com as crianças, foi possível perceber seus interesses e modos de enfrentar os desafios presentes nas atividades propostas. Esse tipo de abordagem propõe que "nada é trivial, que tudo tem potencial para constituir uma pista que nos permita estabelecer uma compreensão mais esclarecedora do nosso objecto de estudo" [Bogdan e Biklen 1994 p. 49].

A realização do trabalho ocorreu na Unidade Universitária de Educação Infantil Núcleo de Desenvolvimento da Criança (UUNDC/UFC), com duas turmas (Infantil 4 e Infantil 5), tendo como suporte tecnológico dois desktops, nos quais era acessado o jogo "Run Marco". As atividades aconteciam de forma gradual para atender às perguntas das crianças, ouvi-las e mediar sua aprendizagem.

Durante o segundo semestre de 2019, as crianças usaram o jogo Run Marco em desktops, recurso disponível na instituição. É importante salientar que a instituição não dispõe de laboratórios móveis, por isso utiliza a Sala de Leitura, espaço amplo onde os desktops para uso pedagógico estão instalados. Ao todo, vinte e seis (26) crianças usaram o jogo Run Marco ao longo de quatro meses (de agosto a novembro), sendo um contato semanal de cada criança com o referido jogo. As crianças eram atendidas em duplas, cada uma utilizando um computador, o que favorecia a interação e a habilidade colaborativa na resolução dos desafios propostos.

O jogo Run Marco foi escolhido pelo fato de atender aos objetivos propostos como estratégia de construção das habilidades definidas pelo PC e possibilitar o trabalho de diferentes conceitos. A decomposição é utilizada para dividir problemas complexos em partes menores, habilidade que, no jogo, é percebida quando as crianças vão unindo os comandos (blocos) aos poucos e, após observarem o resultado, continuam a atividade até chegarem à "estrelinha". O reconhecimento de padrões, de modo a agrupar e relacionar os passos de forma estratégica para solucionar o problema, pode ser percebido: 
diretamente, na interação sujeito-jogo, quando a criança toma atitudes baseando-se em uma percepção de repetições que observa; pelo mediador, que pode observar padrões de comportamento das crianças. A abstração faz-se presente para reconhecer os fatores de geração de um problema, no qual as crianças optam pela melhor forma no jogo, selecionando o que consideram mais importante. Nessa fase, foi importante observar se elas resolviam as proposições do jogo por partes ou se, simplesmente, montavam os blocos de modo aleatório. O algoritmo foi relacionado à ordenação de elementos ou etapas para a solução de uma situação-problema. Os aprendizes podiam escolher entre dois personagens: Marco (personagem que dá nome ao jogo) ou Sophia.

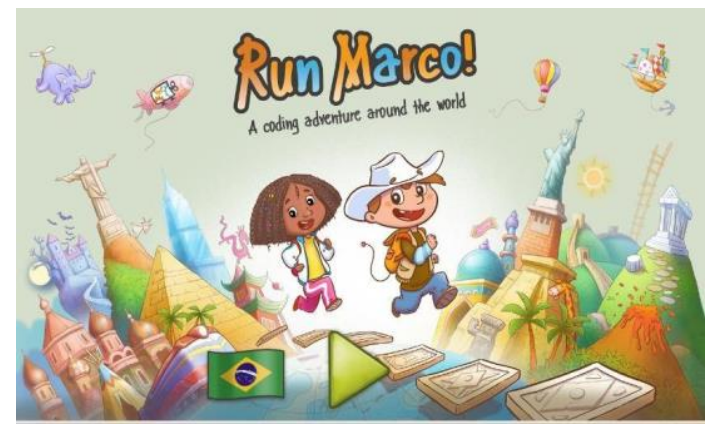

Figura 1. Tela inicial do jogo

O jogo Run Marco utiliza a Linguagem de Programação Visual (Visual Programming Language - VLP), atribuindo comandos a blocos que, quando deslocados para um painel e unidos como se fossem peças de um quebra-cabeça, apresentam funcionalidades. A VLP ocorre "quando a sintaxe de uma linguagem de programação (semanticamente significativa) inclui expressões visuais [Burnett 1999, p.1].

Esse tipo de linguagem torna-se mais adequado para uso na educação, mas é importante enfatizar que esse jogo foi desenvolvido para crianças de seis (6) a doze (12) anos e, pela interface apresentada, em muitos casos, requer uma maior compreensão das linguagens visual e textual. Entretanto, com a mediação de um adulto, o recurso pode ser facilmente utilizado por crianças da Educação Infantil, pois apresenta um design amigável e interativo.

A lógica matemática, a lateralidade e a orientação espacial podem ser trabalhadas de forma divertida e envolvente, possibilitando a colaboração entre as crianças e contribuindo para o processo de socialização.

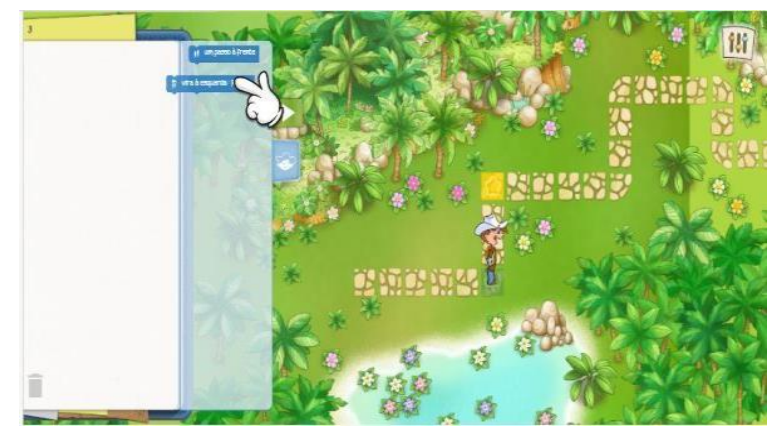

Figura 2: Representação de comandos iniciais (lateralidade) 
O tempo disponibilizado para a atividade dependia da necessidade e do interesse de cada criança, sendo estabelecido que o mais importante era que elas conseguissem entender a proposta do jogo: chegar a um objetivo por meio da montagem de um painel de comandos. Durante esse processo, os registros eram feitos por meio de anotações em um diário de bordo, fotografias e gravações que permitissem uma maior compreensão sobre as contribuições que o jogo poderia oferecer às crianças.

Foi importante observar as relações estabelecidas entre as crianças e o desktop durante o primeiro contato com o jogo. Devido ao fato de a instituição já oferecer o uso dos recursos tecnológicos às crianças de forma pedagógica, o uso do computador de mesa não gerou dificuldades que inviabilizassem as ações.

A ferramenta utilizada para os objetivos do jogo foi o mouse. Para tanto, foram adquiridos dois mouses sem fio, de tamanho pequeno, para a necessária adequação ao tamanho das mãos infantis, o que favoreceu o manuseio.

Duas crianças, pela familiaridade com telas de toque, de início apresentaram certa resistência ao mouse e tentaram tocar a tela do monitor, como se fosse touch screen. Esse fato não constituiu um empecilho, visto que elas compreendiam a natureza do jogo. Com o passar do tempo, a familiaridade com o recurso e a mediação docente, as crianças conseguiram utilizar o mouse com naturalidade.

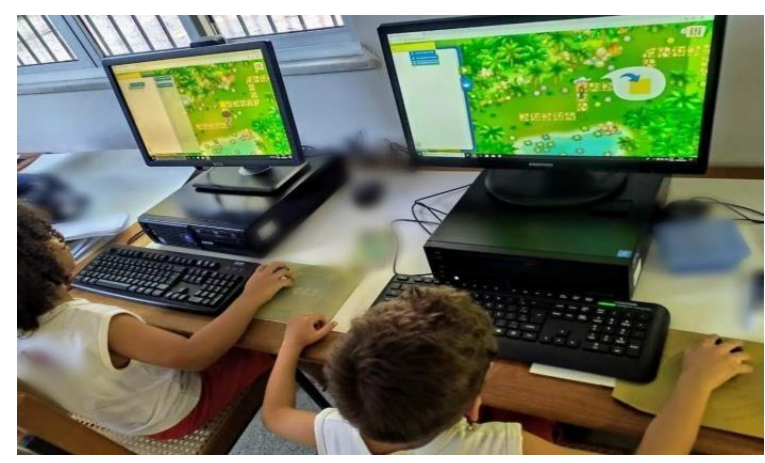

Figura 3: Crianças usando o jogo Run Marco

O tópico seguinte trata das experiências desenvolvidas e dos resultados observados por meio de uma discussão acerca das contribuições pedagógicas do jogo utilizado.

\section{Resultados e discussão}

A partir dos registros feitos, foi possível perceber que essa atividade possibilitou grande engajamento por parte das crianças, demonstrando que situações desafiadoras apresentadas por meio de recursos educacionais digitais são bastante atrativas. Todas as crianças conseguiram entender o objetivo do jogo, ultrapassaram os níveis e obstáculos propostos e ficaram contentes com as conquistas, apresentadas por meio de estrelas na tela do desktop, o que possibilitou, cada vez mais, sua motivação para seguirem no jogo.

Apesar de estarem acostumadas com o manuseio de telas de toque, como tablets e smartphones, o desenvolvimento da atividade foi possível com a colaboração do mediador presente na sala. Além disso, é imprescindível a mediação para a leitura e ajuda na compreensão do jogo, pois as crianças da Educação Infantil, comumente, ainda não leem nem escrevem convencionalmente. 
Participaram do jogo vinte e seis vinte e seis (26) crianças, e todas conseguiram entender o propósito do jogo. À medida que as crianças evoluíam nos níveis, as reações sobre as dificuldades e facilidades que iam aparecendo revelavam seu interesse e as estratégias pensadas para a solução dos problemas propostos.

Das vinte e seis (26) crianças, três (3) foram motivadas a seguir no jogo até os níveis mais avançados (a partir do décimo nível), em que a repetição de um comando, representando a operação multiplicação matemática, era proposta para avançar no jogo.

Observar cada situação de acordo com a perspectiva do PC trouxe uma visão diferenciada, percebendo o comportamento de cada uma. As três crianças que aparesentaram motivação para seguir até os níveis mais avançados utilizaram a habilidade reconhecimento de padrões de forma evidente, quando elas faziam escolhas no jogo, baseando-se na experiência de tentativa e erro que tiveram anteriormente. Elas também demonstravam interesse em resolver as situações de forma autônoma de modo que, quando o mediador interferia, na tentativa de colaborar, rejeitavam a ajuda e buscavam solucionar os desafios sozinhas.

Algumas crianças usavam o horário de intervalo das atividades cotidianas, comumente destinadas às atividades ao ar livre, para jogarem mais tempo além do que já era reservado às atividades. Como a instituição respeita a autonomia e as escolhas das crianças, aquelas que desejassem jogar por mais tempo, podiam fazê-lo, orientadas pelas pesquisadoras. O trabalho foi realizado de forma gradual, das etapas mais simples para as mais complexas, para que cada criança, utilizando o tempo disponível ao desenvolvimento das atividades, fosse atendida, orientada e instigada a pensar.

A importância do jogo Run Marco como instrumento da pesquisa foi contribuir para que as crianças aprendessem com as tentativas durante o jogo, estimulando o raciocínio lógico. Nos níveis iniciais, os relatos da maioria das crianças eram sobre o jogo ser muito fácil. Contudo, à medida que elas avançavam de nível, o jogo apresentava mais desafios e as motivava para a busca de soluções. As crianças usavam o jogo de modo individual, solicitando a colaboração de um colega ou a ajuda do mediador presente.

Utilizar o PC para compreender como as crianças lidavam com os desafios apresentados pelo jogo possibilitou entender como cada criança elaborava seu pensamento na tomada de decisão. Suas expressões de entusiasmo foram registradas a respeito de suas conquistas, como nessa fala: "Esse jogo é muito fácil!" Seu interesse pelo jogo também foi demonstrado: "Posso vir jogar de novo?"

Além disso, as crianças que já demonstravam utilizar recursos tecnológicos digitais, como jogos, apresentavam maior interesse e melhor desempenho na atividade proposta. Diante disso, consideramos importantes os estímulos sobre essa perspectiva da utilização de games como possibilidade de desenvolvimento do PC.

É importante ressaltar alguns desafios vivenciados durante a mediação com as crianças, principalmente pelo fato de o jogo ser projetado para crianças de seis a doze anos de idade e apresentar a necessidade de alguns conhecimentos prévios de leitura textual e simbólica, assim como de orientação espacial e lateralidade. Nesse sentido, algumas especificidades do público-alvo não são totalmente atendidas, especialmente o uso da linguagem escrita. Mas isso não inviabilizou a realização das atividades, pois a mediação docente supriu as lacunas encontradas.

De acordo com as ideias apresentadas, percebemos a importância de pensar em 
ferramentas computacionais e jogos que incentivem a tomada de decisão, o raciocínio lógico, a colaboração, a participação e o engajamento das crianças, desenvolvidos especialmente para atender às especificidades da Educação Infantil.

\section{Conclusões}

Diante dos registros observados, foi notório o envolvimento das crianças, notadamente na utilização de um jogo desafiador, que possibilitou o desenvolvimento da autonomia, do raciocínio lógico e da criatividade. Nesse sentido, as crianças foram capazes de resolver problemas propostos por meio do jogo Run Marco, de forma lúdica, com grande engajamento em todas as etapas.

A utilização do jogo Run Marco contribuiu para a ludicidade, pois aprender brincando favorece o envolvimento das crianças e atende aos eixos fundantes do trabalho pedagógico a ser desenvolvido na Educação Infantil, que são as interações e as brincadeiras. Além disso, por meio da perspectiva do PC foi possível reconhecer as estratégias que as crianças utilizaram, as quais revelaram seus níveis de desenvolvimento e aprendizagem.

Utilizar a abordagem do PC para verificar as estratégias utilizadas pelas crianças durante o percurso do jogo foi importante para reconhecer a importância do trabalho com recursos tecnológicos que desafiem a capacidade de resolução de problemas. O PC pode contribuir, inclusive, para um melhor planejamento das atividades por parte dos educadores e pesquisadores.

Reiteramos a necessidade de que sejam desenvolvidos jogos e estudos na perspectiva do PC para crianças da Educação Infantil, considerando as especificidades dessa faixa etária, sobretudo quanto ao fato de que elas, comumente, ainda não leem nem escrevem convencionalmente.

Pensar nas TDIC como ferramentas que auxiliam no processo de ensino e aprendizagem é necessário não somente como uma forma de inovação educacional, mas para que o caminho das experiências de construção do conhecimento seja facilitador, interessante e motivador.

\section{Referências}

Abbasi, A. Z.; Ting, D. H.; Hlavacs, H. (2017) "Engagement in games: developing an instrument to measure consumer videogame engagement and its validation". International Journal of Computer Games Technology, v. 2017.

Brasil. (2010) "Diretrizes Curriculares Nacionais para a Educação Infantil". Ministério da Educação. Secretaria de Educação Básica. Secretaria de Educação Básica - Brasília: MEC, SEB.

. (2018) "Base Nacional Comum Curricular: educação é a base". Ministério da Educação. Secretaria de Educação Básica. Secretaria de Educação Básica - Brasília: MEC, SEB.

Bogdan, R.; Biklen, S. (1994) "Investigação qualitativa em educação: uma introdução à teoria e aos métodos". Porto Editora. 
Burnett, Margaret M. (1999). "Visual programming". Wiley Encyclopedia of Electrical and Electronics Engineering.

Carlos, L.; Godinho, J.; Gomide, J. (2018). "Um Relato de Experiência da Escola de Verão de Programação para Crianças". In: Anais do Workshop de Informática na Escola (Vol. 24, No. 1, p. 41).

Gomes, T.; Melo, J.; Tedesco, P. (2016) "Jogos Digitais no Ensino de Conceitos de Programação para Crianças". Brazilian Symposium on Computers in Education (Simpósio Brasileiro de Informática na Educação - SBIE), 27(1), 470.

Kenski, V. M. (2007) "Educação e tecnologias: o novo ritmo da informação". Campinas, São Paulo, Papirus.

Kotz, A; Kovatli, M. F. (2019) "O Pensamento Computacional como Ponte para o Ensino de Robótica”. In: Revista Tecnologias na Educação. Edição Temática XII. Rio Grande do Sul.

Meira, L; Blikstein, P. (2020) "Ludicidade, jogos digitais e gamificação na aprendizagem". Porto Alegre: Penso Editora.

Papert, Spc. (1985) “Logo: computadores e educação”. São Paulo: Brasiliense. . (2008) "A Máquina das Crianças: repensando a escola na era da informática”. Porto Alegre: Artmed.

Prensky, M. (2001) "Nativos digitais, imigrantes digitais". In: On the Horizon, 9(5), 1-6.

Ramos, J.; Espadeiro, R. (2014) “Os futuros professores e os professores do futuro: desafios da introdução ao pensamento computacional na escola, no currículo e na aprendizagem". In: Educação, Formação \& Tecnologias - ISSN 1646-933X, América do Norte. Disponível em: <http://eft.educom.pt/index.php/eft/article/view/462>. Acesso em: 22 Mai. 2020.

Santana, S. J.; Oliveira, W. (2019) "Desenvolvendo o Pensamento Computacional no Ensino Fundamental com o uso do Scratch". In: Anais do Workshop de Informática na Escola, [S.1.], p. 158. ISSN 2316-6541.

Silva, Débora Juliane; Guarda, Graziela. (2019) "CriptoData: ensino de Criptografia via Computação Desplugada". Anais dos Workshops do Congresso Brasileiro de Informática na Educação, [S.1.], p. 248, nov.. ISSN 2316-8889. Disponível em: <https://www.br-ie.org/pub/index.php/wcbie/article/view/8966>. Acesso em: 25 jul. 2020.

Sociedade Brasileira de Computação. (2018) "Diretrizes para ensino de Computação na Educação Básica”. Disponível em: <http://sbc.org.br/documentos-da-sbc/send/203educacao-basica/1220-bncc-em-itinerario-informativo-computacao-2>.

Wing, J. (2006). "Computational thinking". Communications of the Association for Computing Machinery, pp. 152-155.

(2008) "Computational thinking and thinking about computing”. Philosophical Transactions of the Royal Society A: Mathematical, Physical and Engineering Sciences, v. 366, n. 1881, p. 3717-3725. 